\title{
Analysis of $\beta$-lactamase phenotypes and carriage of selected $\beta$-lactamase genes among Escherichia coli strains obtained from Kenyan patients during an 18-year period
}

John Kiiru ${ }^{1,2,3^{*}}$, Samuel Kariuki ${ }^{1 \dagger}$, Bruno M Goddeeris ${ }^{2,4+}$ and Patrick Butaye ${ }^{3,5+}$

\begin{abstract}
Background: Although $\beta$-lactam antibiotics are heavily used in many developing countries, the diversity of $\beta$-lactamase genes (b/a) is poorly understood. We screened for major $\beta$-lactamase phenotypes and diversity of bla genes among 912 E. coli strains isolated from clinical samples obtained between 1992 and 2010 from hospitalized and non-hospitalized patients.

Results: None of the isolates was resistant to carbapenems but $30 \%$ of all isolates were susceptible to cefepime, cephamycins and piperacillin-tazobactam. Narrow spectrum $\beta$-lactamase (NSBL) phenotype was observed in $278(30 \%)$ isolates that contained bla $a_{T E M-1}(54 \%)$ or bla $a_{S H V-1}(35 \%)$ or both (11\%). Extended Spectrum $\beta$-lactamase (ESBL) phenotype was detected in 247 (27\%) isolates which carried bla bla $a_{C T X-M-15}(24 \%)$, bla $a_{C T X-M-9}(2 \%)$, bla $a_{C T X-M-8}(4 \%), b l a_{C T X-M-3}(11 \%)$, bla $a_{C T X-M-1}(6 \%)$, bla $a_{S H V-5}(3 \%)$, bla $a_{S H V-12}$ (5\%), and bla $a_{\text {TEM-52 }}(16 \%)$. Complex Mutant TEM-like (CMT) phenotype was detected in 220 (24\%) isolates which carried bla $a_{T E M-125}(29 \%)$, while bla TEM-50, bla $a_{\text {TEM-78, }}$ bla TEM-109, bla $a_{T E M}-152$ and bla $a_{T E M-158}$ were detected in lower frequencies of between $7 \%$ and $11 \%$. Majority of isolates producing a combination of CTX-M-15+OXA-1 + TEM-1 exhibited resistance phenotypes barely indistinguishable from those of CMT-producers. Although 73 (8\%) isolates exhibited Inhibitor Resistant TEM-like (IRT) phenotype, bla $a_{T E M-103}$ was the only true IRT-encoding gene identified in $18(25 \%)$ of strains with this phenotype while the rest produced a combination of TEM-1 + OXA-1. The pAmpCs-like phenotype was observed in 94 (10\%) isolates of which 77 (82\%) carried blacmY-2 while 18\% contained bla CMY-1. $_{\text {. }}$

Isolates from urine accounted for 53\%,53\%,74\% and $72 \%$ of strains exhibiting complex phenotypes such as IRT, ESBL, CMT or pAmpC respectively. On the contrary, 55\% isolates from stool exhibited the relatively more susceptible NSBL-like phenotype. All the phenotypes, and majority of the bla genes, were detected both in isolates from hospitalized and non-hospitalized patients but complex phenotypes were particularly common among strains obtained between 2000 and 2010 from urine of hospitalized patients.

Conclusions: The phenotypes and diversity of bla genes in E. coli strains implicated in clinical infections in non-hospitalized and hospitalized patients in Kenya is worryingly high. In order to preserve the efficacy of $\beta$ lactam antibiotics, culture and susceptibility data should guide therapy and surveillance studies for $\beta$-lactamaseproducers in developing countries should be launched.
\end{abstract}

\footnotetext{
* Correspondence: jndemi@yahoo.com

${ }^{\dagger}$ Equal contributors

'Centre for Microbiology Research, Kenya Medical Research Institute, P.O Box 19464-00202, Nairobi, Kenya

2Department of Biosystems, Faculty of Bio-Science Engineering, Katholieke Universiteit Leuven, Kasteelpark Arenberg 30, B-3001, Heverlee, Belgium

Full list of author information is available at the end of the article
} 


\section{Background}

$\beta$-lactam antibiotics are an important arsenal of agents used against both Gram-negative and Gram-positive bacteria. Resistance to this class of antimicrobials is therefore of immense clinical significance. It is important to investigate the epidemiology of strains that are resistant to $\beta$-lactam antibiotics especially in Sub-Saharan Africa where treatment with alternative or more effective agents may be beyond the reach of majority of patients. Before treatment using $\beta$-lactam antibiotics is initiated, proper and timely identification of the $\beta$-lactamase phenotype is of critical importance. Failure or delay to do this may lead to therapeutic failure and death of patients [1]. In order to guide therapy and in order to understand the molecular epidemiology of $\beta$-lactamaseproducers, a combination of susceptibility profiling, PCR and sequencing techniques may be required [2-4]. These techniques are not always available or affordable in resource-poor settings. Therefore, the prevalence of $\beta$ lactamases in developing countries is largely undetermined and the use of $\beta$-lactam antibiotics in such countries remains largely empiric.

Based on resistance to $\beta$-lactam/ $\beta$-lactamase inhibitor antibiotics, bacteria strains may be conveniently categorized into various resistant phenotypes [5]. Strains exhibiting Narrow Spectrum $\beta$-lactamase Phenotypes (NSBLs) normally produce TEM-1 and/or SHV-1 enzymes that effectively degrade penicillins but are susceptible to other classes of $\beta$-lactams [6]. However, mutations on the promoter region of the gene encoding TEM-1 may result to over-production of these otherwise narrow-spectrum enzymes. This overproduction may in turn confer resistance to other classes of $\beta$-lactams besides penicillins [7-10]. Point mutations on these enzymes may also generate inhibitor resistant enzymes such as the Inhibitor Resistant TEMs (IRTs) that degrade penicillins but are not impeded by $\beta$-lactamase inhibitors such clavulanic acid or sulbactam [4,11]. Extended Spectrum $\beta$-Lactamases (ESBLs) may also be derived from TEM- and SHV-type enzymes. ESBLs exhibit a wide hydrolytic ability to different generations of cephalosporins but remain susceptible to $\beta$-lactamase inhibitors [12]. Complex Mutant TEMs (CMTs) are also derived from TEM-1 or TEM- 2 and degrade most $\beta$ lactams but are susceptible to $\beta$-lactamase inhibitors including tazobactam. The CMTs are also susceptible to cephamycins and carbapenems [13]. Plasmid-encoded AmpC (pAmpC) such as CMYs mediate resistance to most classes of $\beta$-lactams except to fourth generation cephalosporins and carbapenems [14]. The $\beta$-lactamases with the worst clinical implications are those that degrade carbapenems, the most potent class of $\beta$-lactam antibiotics available today. Some carbapenemases such as the Klebsiella pneumoniae carbapenemases (KPC) degrade virtually all classes of $\beta$-lactams [15-17]. Some carbapenemases such as metallo- $\beta$-lactamases (MBLs) are however susceptible to aztreonam, a monobactam [18]. It is therefore clear that determination of $\beta$ lactamase phenotypes may not only aid the choice of agents to treat patients but may also guide the screening of bla genes and therefore save costs in surveillance studies. Understanding molecular epidemiology of bla gene is also important because majority of broadspectrum resistant enzymes, especially the ESBLs and CMYs are encoded in conjugative plasmids that may be acquired across species barrier. Therefore, such genes have a high potential for spread via horizontal gene transfer mechanisms [19-22].

The phenotypic diversity of $\beta$-lactamase-producers in Kenya is poorly described and the diversity of bla genes has not been properly investigated [23-28]. The aim of the current study was to determine the $\beta$-lactamase phenotypes and carriage of bla genes of critical importance in E. coli obtained from blood, stool and urine obtained from hospitalised and non-hospitalised patients seeking treatment in Kenyan hospitals during an 18-year period (1992 to 2010).

\section{Results}

\section{Phenotypic diversity of $\beta$-lactamase-producers}

None of the 912 isolates tested in this study were resistant to carbapenems. Cefepime, (a fourth generation cephalosporin), cefoxitin (a cephamycin), and piperacillin-tazobactam (TZP), were effective against majority $(60 \%)$ of these isolates. The NSBL-like phenotype was the most dominant phenotype in our collection and was observed in 278 (30\%) of the 912 isolates compared to $73(8 \%), 247$ (27\%), $220(24 \%)$ and $94(10 \%)$ of isolates found to exhibit IRT-, ESBL-, CMT and pAmpC-like phenotypes respectively, Table 1 . Based on resistance phenotypes, 247 ESBL-producers fit into two sets. The first set comprised of 142 isolates exhibiting resistance to combinations of aztreonam and multiple cephalosporins including ceftazidime. The other set of 105 isolates were resistant to the same panel of antibiotics but not to ceftazidime. The 220 isolates with a CMT-like phenotype were resistant to all generations of cephalosporins but were susceptible to cephamycins and carbapenems. Resistance to all $\beta$-lactamase inhibitors including TZP was observed in 160 (73\%) of the CMTproducers. Among 40 isolates with a CMT-like phenotype that had intermediate resistance to TZP, tiny ghost zones $(\leq 3 \mathrm{~mm})$ were observed between amoxicillinclavulanic acid (AMC) and ceftazidime (CAZ) and/or Cefotaxime (CTX). These isolates therefore exhibited a combination of both ESBL- and CMT-like phenotypes. The most resistant strains were those exhibiting a pAmpC-like phenotype. These 94 isolates comprising 
Table $1 \beta$-lactamase phenotypes encountered among the 912 strains analyzed

\begin{tabular}{|c|c|c|c|c|c|c|}
\hline \multicolumn{7}{|c|}{ Antibiotics to which isolates were resistant } \\
\hline $\begin{array}{l}\text { Penicillins, 1st \& } \\
\text { 2nd generation } \\
\text { cephalosporins }\end{array}$ & $\begin{array}{l}\text { 3rd Generation } \\
\text { cephalosporins \& } \\
\text { Monobactams }\end{array}$ & $\begin{array}{l}\text { 4th Generation } \\
\text { cephalosporins }\end{array}$ & inhibitors & Cephamycins & Most probable Phenotype $^{a}$ & Total $(\%) n=912$ \\
\hline AMP, KF, AMX & - & - & - & - & NSBL & $103(11)$ \\
\hline AMP, AMX, KF OXA & - & - & - & - & NSBL & $175(19)$ \\
\hline AMP, AMX, KF OXA & - & - & AMC, AMS & - & IRT & $65(7)$ \\
\hline AMP, KF, AMX, & - & - & AMC, AMS & - & IRT & $8(1)$ \\
\hline AMP, AMX, KF, CXM & $C T X^{b}, A Z T^{b}$ & - & - & - & ESBL & $105(12)$ \\
\hline AMP, AMX, KF, CXM & $C T X, C A Z^{*}, A Z T$ & - & - & - & ESBL & $75(8)$ \\
\hline AMP, AMX, OXA KF, CXM & $C T X^{b}, C A Z^{b}, A Z T$ & FEP & AMS & - & ESBL & $67(7)$ \\
\hline AMP, AMX, OXA KF, CXM & $C T X, C A Z^{*}, A Z T$ & FEP & AMC, AMS & - & CMT & $40(4)$ \\
\hline AMP, AMX, OXA, KF, CXM & CTX, CAZ, AZT & FEP & AMC, AMS, TZP & - & CMT & $180(20)$ \\
\hline AMP, AMX, OXA KF, CXM & CTX, CAZ, AZT & FEP & AMC, AMS, TZP & FOX & pAmpC & $94(10)$ \\
\hline
\end{tabular}

Resistance phenotypes of the 912 isolates investigated.
a: $\beta$-lactamase phenotypes observed in different isolates were defined as follow:- Narrow spectrum $\beta$-lactamases (NSBLs) were resistant to penicillins but were susceptible to other classes of $\beta$-lactam antibiotics.

a: $\beta$-lactamase phenotypes observed in different isolates were defined as follow:- Narrow spectrum $\beta$-lactamases (NSBLs) were resistant to penicillins but were susceptible to other Isolates exhibiting the inhibitor resistant TEM phenotype (IRT) were those capable of degrading penicilins, were not inhibited by $\beta$-lactamase inhibitors but were susceris
ESBL-producers were resistant to penicillins, $2^{\text {nd }}$ and most $3^{\text {rd }}$ generation cephalosporins, and exhibited intermediate resistance to $4^{\text {th }}$ generation cephalosporins and were fully susceptible to cephamycins,

carbapenems and $\beta$-lactamase inhibitors. The complex mutant TEMs (CMTs) were resistant to most $\beta$-lactams and $\beta$-lactamase inhibitors including TZP but were susceptible to cephamycins and carbapenems. Isolates with the $\mathrm{pAmpC}$ phenotypes were resistant to all generations of $\beta$-lactam antibiotics, were susceptible to carbapenems and were either susceptible or exhibited intermediate resistance to $4^{\text {th }}$ generation cephalosporins.

appearance of zones of synergy between a given cephalosporin or monobactam and amoxicillin-clavulanic acid (AMC).

$(-)$ isolate with a given phenotype were susceptible to a given set of antibiotics. 
about $10 \%$ of all the isolates in our collection were resistant to most generations of cephalosporins and $\beta$ lactamase inhibitors including TZP but were susceptible to carbapenems.

\section{Distribution of $\beta$-lactamase-producers}

All the $\beta$-lactamase phenotypes reported in this study were observed in isolates from all specimen-types obtained during the 1990s and 2000s and from both hospitalized and non-hospitalized patients, Table 2. While majority of isolates from stool exhibited the relatively susceptible NSBL-like phenotype, isolates from urine accounted for 55\%, 53\%, 57\% and 72\% of strains with complex resistances such as IRT-, ESBL-, CMTand $\mathrm{pAmpC}$-like phenotypes respectively. Majority of isolates from hospitalized patients, especially those diagnosed with UTIs, exhibited such complex phenotypes compared to those obtained from patients seeking outpatient treatment. These complex resistances were also more common among isolates obtained in recent years (2000-2010).

\section{Carriage of bla genes}

Carriage of $b l a_{T E M-1}$ or $b l a_{S H V-1}$ was associated with the NSBL-like phenotype in $54 \%$ and $35 \%$ of the 155 isolates exhibiting this phenotype respectively. The two genes were also found together in $11 \%$ of the NSBL-producers, Table 3. The only IRT-encoding gene identified in this study was $b l a_{T E M-103}$ that was detected in 18 (25\%) of the 73 isolates with an IRT-like phenotype. The other 55 (75\%) of isolates with this phenotype carried a combination of $b l a_{T E M-1+} b l a_{O X A-1}$ genes. Majority $(78 \%)$ of the 247 isolates with an ESBL-like phenotype tested positive for CTX-M-type ESBLs. While bla $a_{C T X-M-14}$ and bla $a_{C T X-}$ $M-15$ were detected in $29 \%$ and $24 \%$ of these isolates respectively, $\quad b l a_{C T X-M-1}, \quad b l a_{C T X-M-3}, \quad b l a_{C T X-M-9}$ and $b l a_{C T X-M-8}$ were detected in lower frequencies of $6 \%$, $11 \%, 2 \%$ and $4 \%$ respectively, Table 3 . Isolates which carried $b l a_{C T X-M-1}$ alone exhibited intermediate resistances to aztreonam and cefotaxime and were fully susceptible to ceftazidime. The $b l a_{T E M-52}$ that was detected in 22 (16\%) of ESBL-producers was the only TEM-type ESBL identified in this study. The carriage and diversity of SHV-type ESBL genes was also low in which case, only $b l a_{S H V-5}$ and $b l a_{S H V-12}$ ESBL-encoding genes were detected in $3 \%$ and $5 \%$ of the ESBL-producers respectively. Resistance to ceftazidime among the ESBLproducers was attributed mainly to carriage of $b l a_{C T X-M-15}$ or a combination of $b l a_{C T X-M s}+b l a_{O X A-1}+b l a_{T E M-1}$ genes. A significant proportion (39\%) of isolates containing bla $_{C T X-M s}$ or bla $a_{S H V}$ type ESBLs in the absence of bla $a_{O X A-1}$ or $b l a_{T E M-1}$ were susceptible to ceftazidime.

The $b l a_{T E M-125}$ was detected in $29 \%$ of the 124 isolates exhibiting a CMT-like phenotype and was therefore the most common CMT-encoding gene detected in this study. Other CMT genes: - bla $a_{T E M-50}$, bla $a_{T E M-78}, b l a_{T E M-152}$ and $b l a_{T E M-158}$ were detected in much lower prevalences of $8 \%$, $7 \%, 11 \%$, and $8 \%$ respectively, Table 3 . Carriage of CMT genes did not account for CMT-like phenotypes in 30\% of isolates with this phenotype. Nine of such isolates tested positive for a combination of $b l a_{T E M-14}+b l a_{O X A-1+} b l a_{T E M-1}$ while 14 strains carried a combination of $b l a_{T E M-15}+$ $b l a_{O X A-1+} b l a_{T E M-1}$. Another 15 isolates tested positive for a combination of a $b l a_{T E M-52}$ (a TEM-type ESBL gene), and $b l a_{O X A-1}$. Production of OXA-1 and TEM-1 enzymes in the presence of CTX-M enzymes apparently masked the ESBL-phenotype that is otherwise conferred by CTX-M enzymes. Therefore, isolates producing a combination of such enzymes could hardly be distinguished from genuine CMT-producers. The bla $a_{C M Y-2}$ that was present in 77 $(72 \%)$ of all isolates in our collection was the most common pAmpC-encoding genes detected in this study. The CMYs were also detected in strains co-producing TEM-1 and SHV-type ESBLs suggesting a possible co-evolution of penicillinases, ESBLs and AmpCs genes in the same isolate. While majority of $b l a_{O X A-1}$ genes were detected in strains bearing ESBL genes such as bla $a_{C T X-M s}$ or $b l a_{T E M-52 \text {, the }}$ bla $a_{O X A-2}$ were detected in strains carrying bla $a_{C M Y s}$ Table 3. None of the isolates investigated tested positive for bla-PERlike, $b l a_{A C C}$ like, $b l a_{V E B}$-like, or $b l a_{D H A}$ like genes.

\section{Distribution of bla genes}

We also analyzed for the distribution of bla genes among strains obtained from different specimen-types

Table 2 Clinical background of strains exhibiting different $\beta$-lactamase phenotypes

\begin{tabular}{|c|c|c|c|c|c|c|c|c|}
\hline & & & ecimen-ty & & Pati & tegory & Yea & ation \\
\hline & Total & Stool & Urine & Blood & Inpatient & Outpatient & $1990 \mathrm{~s}$ & $2000 s$ \\
\hline NSBL & 278 & $153(55)$ & $39(14)$ & $86(31)$ & $82(29)$ & $196(71)$ & $186(67)$ & $91(33)$ \\
\hline IRT & 73 & $18(25)$ & $38(53)$ & $17(22)$ & $60(82)$ & $13(18)$ & $28(38)$ & $45(62)$ \\
\hline ESBL & 247 & $65(26)$ & $130(53)$ & $52(21)$ & $170(69)$ & 77 (31) & 79 (32) & $168(68)$ \\
\hline CMT & 220 & $21(10)$ & $163(74)$ & $36(16)$ & $163(74)$ & $57(26)$ & $62(28)$ & $158(72)$ \\
\hline pAmpC & 94 & $13(14)$ & $68(72)$ & $13(14)$ & $87(92)$ & 7 (8) & $12(13)$ & $82(87)$ \\
\hline
\end{tabular}

Number (\%) of isolates exhibiting a given phenotype among those obtained from different specimen-types and different category of patients during the 1990s and 2000s period. 
Table 3 Combination of $\beta$-lactamases detected in 586 strains analyzed

\begin{tabular}{|c|c|c|c|c|c|}
\hline & NSBL & IRT & ESBL & CMT & pAmpC \\
\hline$\beta$-lactamase genes & $\overline{n=155}$ & $\overline{n=73}$ & $\overline{n=140}$ & $\overline{n=124}$ & $\mathrm{n}=94$ \\
\hline TEM-1 & $84(54)$ & - & - & - & - \\
\hline SHV-1 & $54(35)$ & - & - & - & - \\
\hline TEM-1 and OXA-1 & - & $55(75)$ & - & - & - \\
\hline TEM-1 + SHV-1 & $17(11)$ & - & - & - & - \\
\hline SHV-5 & - & - & $4(3)$ & - & - \\
\hline SHV-12 & - & - & $7(5)$ & - & - \\
\hline CTX-M-1 + OXA-1 & - & - & $9(6)$ & - & - \\
\hline CTX-M-3 & - & - & $15(11)$ & - & - \\
\hline CTX-M-8 & - & - & $6(4)$ & - & - \\
\hline CTX-M-9 & - & - & $3(2)$ & - & - \\
\hline CTX-M-14 & - & - & $41(29)$ & - & - \\
\hline CTX-M-14 + TEM-1 + OXA-1 & - & - & - & $9(7)$ & - \\
\hline CTX-M-15 & - & - & $34(24)$ & - & - \\
\hline CTX-M-15 + TEM-1 + OXA-1 & - & - & - & $14(11)$ & - \\
\hline TEM-103 & - & $18(25)$ & - & - & - \\
\hline TEM-109 & - & - & - & $9(7)$ & - \\
\hline TEM-50 & - & - & - & $10(8)$ & - \\
\hline TEM-52 & - & - & $22(16)$ & - & - \\
\hline TEM-52 + OXA-1 & - & - & - & $15(12)$ & - \\
\hline TEM-78 & - & - & - & $9(7)$ & - \\
\hline TEM-125 & - & - & - & $36(29)$ & - \\
\hline TEM-152 & - & - & - & $14(11)$ & - \\
\hline TEM-158 & - & - & - & $10(8)$ & - \\
\hline$C M Y-1+O X A-2$ & - & - & - & - & $16(17)$ \\
\hline CMY-1 & - & - & - & - & $1(1)$ \\
\hline CMY-2 & - & - & - & - & $5(5)$ \\
\hline CMY-2 + SHV-5 + TEM-1 & - & - & - & - & $14(15)$ \\
\hline CMY-2 + SHV-12 & - & - & - & - & $12(13)$ \\
\hline $\mathrm{CMY}-2+\mathrm{OXA}-2$ & - & - & - & - & $46(49)$ \\
\hline
\end{tabular}

Combination of bla genes detected in isolates exhibiting different $\beta$-lactamase phenotypes.

$(-)$ isolate with a given phenotype did not test positive for a given set of bla genes.

and among those obtained from hospitalized and nonhospitalized patients, Figure 1. Majority of bla genes were present in all specimen-types regardless of their clinical backgrounds. However, bla $a_{C T X-M-3}$ was only detected in isolates from urine while $b a_{T E M-78}$ was not detected among isolates from blood. bla $a_{T E M-109}$ and $b l a_{C T X-M-8}$ on the other hand, were exclusively detected among isolates obtained from hospitalized patients. All bla genes described in this study were found in isolates obtained from both the 1990s and 2000s except bla ${ }_{C M Y-1}$ that was exclusively detected among isolates obtained during the 2000-2010 period.

\section{Discussion}

In this study, we describe the diversity of $\beta$-lactamase genes in a large collection of $E$. coli from different types of clinical specimen obtained from hospitalized and non-hospitalized patients in Kenya. This study suggests that carbapenems and to a less extent, cefepime, cephamycins and piperacillin-tazobactam may still be potent against majority of the isolates investigated. Although we do not rule out that the panel of bla genes in our strains is wider than what is reported in this study, there was a general agreement between phenotypic data and the panel of bla genes detected in the strains analysed. The 
Table 4 Primers used for screening for $\beta$-lactamase genes

\begin{tabular}{|c|c|c|c|c|c|}
\hline Target Gene & Primer name & 5'-3' sequence & $\mathrm{T}^{\circ} \mathrm{C}$ & Size (bp) & Gene accession number \\
\hline \multirow[t]{2}{*}{ blaTEM } & TEM-F & ATGAGTATTCAACAT TTC CG & 55 & 840 & EF125012-related \\
\hline & TEM-R & CCAATGCTTAATCAG TGA GG & & & \\
\hline \multirow[t]{2}{*}{ blaSHV } & SHV-F & TTCGCCTGTGTATTATCTCCCTG & 50 & 854 & AF148850-related \\
\hline & $\mathrm{SHV}-\mathrm{R}$ & TTAGCGTTGCCAGTGYTCG & & & \\
\hline \multirow[t]{2}{*}{ blaCTX-M concensus } & MA1 & ATGTGCAGYACCAGTAARGTKATGGC & 60 & 593 & Y10278-related \\
\hline & MA2 & TGGGTRAARTARGTSACCAGAAYCAGCGG & & & \\
\hline \multirow[t]{2}{*}{ CTX-M group I } & CTXM1-F3 & GAC GAT GTC ACT GGC TGA GC & 55 & 499 & X92506-related \\
\hline & CTXM1-R2 & AGC CG C CGA CGC TAA TAC A & & & \\
\hline \multirow[t]{2}{*}{ CTX-M group $\|$} & TOHO1-2 F & GCG ACC TGG TTA ACT ACA ATC C & 55 & 351 & X92507-related \\
\hline & TOHO1-1R & CGG TAG TAT TGC CCT TAA GCC & & & \\
\hline \multirow[t]{2}{*}{ CTX-M group III } & CTXM825F & CGC TाT GCC ATG TGC AGC ACC & 55 & 307 & AF189721-related \\
\hline & CTXM825R & GCT CAG TAC GAT CGA GCC & & & \\
\hline \multirow[t]{2}{*}{ CTX-M group IV } & CTXM914F & GCT GGA GAA AAG CAG CGG AG & 62 & 474 & AF252622-related \\
\hline & CTXM914R & GTA AGC TGA CGC AAC GTC TG & & & \\
\hline \multirow[t]{2}{*}{ blaCMY (consensus) } & CF1 & ATGATGAAAAAATCGTTATGC & 55 & 1200 & U77414-related \\
\hline & CF2 & TTGCAGCTITTCAAGAATGCGC & & & \\
\hline \multirow[t]{2}{*}{ blaCMY-1 group } & CMY-1 F & GTGGTGGATGCCAGCATCC & 58 & 915 & AJ291609-related \\
\hline & CMY-1R & GGTCGAGCCGGTCTTGTTGAA & & & \\
\hline \multirow[t]{2}{*}{ blaCMY-2 group } & CMY-2 F & GCACTTAGCCACCTATACGGCAG & 58 & 758 & AF305559-related \\
\hline & CMY-2R & GCTTTCAAGAATGCGCCAGG & & & \\
\hline \multirow[t]{2}{*}{ blaOXA-1 } & OXA-1 F & ATGAAAAACACAATACATATCAACTTCGC & 62 & 820 & JO2967-related \\
\hline & OXA-1R & GTGTGTTTAGAATGGTGATCGCATT & & & \\
\hline \multirow[t]{2}{*}{ blaOXA-2 } & OXA-2 F & ACGATAGTTGTGGCAGACGAAC & 62 & 602 & AF300985-related \\
\hline & OXA-2R & ATYCTGTTTGGCGTATCRATATTC & & & \\
\hline \multirow[t]{2}{*}{ blaPER-concensus } & PER-F & ATGAATGTCATTATAAAAGC & 55 & 925 & Z21957-related \\
\hline & PER-R & AATTTGGGTTAGGGCAGAA & & & \\
\hline \multirow[t]{2}{*}{ blaAcC-like } & ACC-F & AGCCTCAGCAGCCGGTTAC & 53 & 818 & AJ133121-related \\
\hline & ACC-R & GAAGCCGTTAGTTGATCCGG & & & \\
\hline \multirow[t]{2}{*}{ blaVEB-concensus } & VEB-F & ATTTAACCAGATAGGACTACA & 55 & 1000 & Z21957-related \\
\hline & VEB-R & CGGTTTGGGCTATGGGCAG & & & \\
\hline \multirow[t]{2}{*}{ blaDHA-concensus } & DHA-F & TGATGGCACAGCAGGATATTC & 55 & 997 & EF406115-related \\
\hline & DHA-R & GCTITGACTCTITCGGTATTCG & & & \\
\hline
\end{tabular}

Primer combinations used for screening and sequencing bla genes. The consensus primers were used for screening and sequencing purposes except for $b / a_{C T X-M}$ and $b l_{O X A}$ that were sequenced using group-specific primers. CTX-M group I primers detect genes encoding CTX-M $-1,-3,-10$ to $-12,-15,-22,-23,-28,-29$ and -30 while primers for CTX-M group II primers detect genes encoding CTX-M-2, $-4,-7$, and -20 . Group III primers detect only CTX-M-8 while group IV primers detect genes encoding CTX-M-9, $-13,-14,-16$ to $19,-21$, and 27 .

$\mathrm{T}^{\circ} \mathrm{C}$ : annealing temperature.

$\mathrm{Y}=\mathrm{T}$ or $\mathrm{C}, \mathrm{R}=\mathrm{G}$ or $\mathrm{A}, \mathrm{S}=\mathrm{G}$ or $\mathrm{C}, \mathrm{K}=\mathrm{G}$ or $\mathrm{T}$.

diversity of bla genes encountered in isolates from blood, stool and urine specimen of hospitalized patients was almost identical to the panel of genes encountered in corresponding specimens from non-hospitalized patients. This partially suggests a possible exchange of strains between hospitalized and non-hospitalized patients or a flow of genes among strains from different clinical backgrounds. Based on the resistance profiles, we identify ESBL-, CMT- and pAmpC-producers as the most important set of strains whose spread in hospital and community settings should be closely monitored. If the prevalence of isolates with such highly resistant strains continues to rise, majority of $\beta$-lactam antibiotics may cease to be effective agents for management of community- and hospital-acquired infections in Kenya.

It is highly likely that heavy use of antibiotics to treat different infections, and urethral tract infections (UTI) in particular, has selected for isolates carrying multiple 


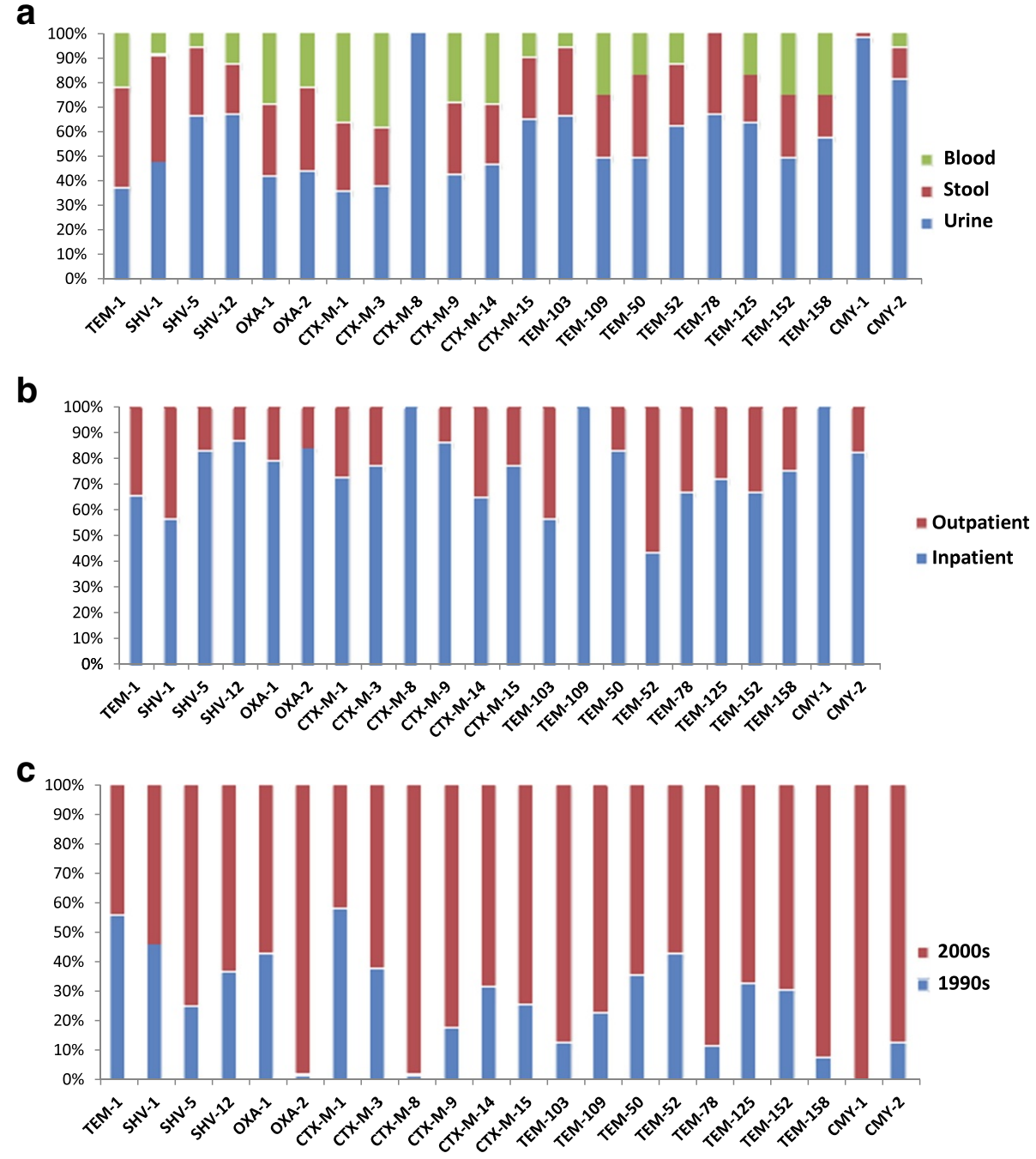

Figure 1 Occurrence of bla genes among isolates from different clinical backgrounds. 1a: Occurrence of bla genes among isolates from blood, stool and urine, 1 b: Occurrence of bla genes among isolates from inpatient and outpatient populations: 1c: Occurrence of bla genes among isolates obtained in the 1990 s and 2000 s periods.

bla genes such as those encountered in this study. Since the antibiotic-use policy is rarely enforced in Kenya, and since most prescriptions are issued without culture and susceptibility data, $\beta$-lactam antibiotics are likely to be glossily misused. This may partially explain why complex phenotypes such as ESBL-, CMT- and pAmpC-like phenotypes were observed even among isolates from stool. The current study also shows that $41 \%$ of the isolates were resistant to at least one $\beta$-lactamase inhibitor. High resistances to inhibitor antibiotics may emerge as a result of over-reliance on amoxicillin-clavulanic acid to treat different infections in Kenya even without a valid prescription. It is however interesting to note that the prevalence of inhibitor resistant bla genes is still very low among strains exhibiting an IRT-like phenotype. Similar studies conducted in Spain reported a similar low prevalence of IRTs [29,30]. The only true IRT reported in this study was TEM-103 while majority (75\%) of isolates with an IRT-like phenotype carried a combination of $b l a_{T E M-1}+b l a_{O X A-1}$. These two genes were also frequently detected in isolates exhibiting a combination of an ESBL- and CMT-like phenotypes. However, $b l a_{O X A-1}$ and $b l a_{T E M-1}$ were also detected in isolates susceptible to inhibitors. We speculate that besides conferring resistance to narrow spectrum penicillins, some TEM-1 and OXA-1 may be implicated in resistance to other classes of antimicrobials such as various generations of cephalosporins and possibly, $\beta$-lactam $/ \beta$-lactamase inhibitor combinations. These hypothesis is partially based on findings from a recent study conducted in Kenya that described novel bla $a_{O X A-1}$ enzymes in Salmonella strains that contain promoter mutations 
that confer resistance to broad-spectrum $\beta$-lactam antibiotics including $\beta$-lactamase inhibitors [23]. Furthermore, studies conducted elsewhere have also reported resistance to multiple $\beta$-lactam antibiotics due to promoter mutations that result to over-production of TEM1 enzymes [30]. It is therefore important to further investigate genetic basis of resistance and the role of these otherwise narrow-spectrum $\beta$-lactamases (TEM-1 and OXA-1) in mediating resistance to advanced classes of $\beta$-lactam antibiotics in developing countries.

In the current study, we found a high diversity of CMTs, yet these enzymes have been reported only in a few countries [13]. It is possible that the ease of access to $\beta$-lactam/ $\beta$-lactamase inhibitor combinations in Kenya without valid susceptibility data has selected for strains with CMT genes that are rarely reported from other countries. In contrast, majority of CTX-M- and SHV-type ESBLs and CMY-type pAmpCs genes identified are those with a global-like spread pattern [31-39]. Similarly, TEM-52, the only TEM-type ESBL reported in this study, is frequently reported in USA [39] and Europe [40]. The wide dissemination of genes encoding these ESBLs and pAmpCs is attributed to physical association between these genes and mobile genetic elements such as ISEcp 1, transposons and conjugative plasmids [41-43]. Such genetic affiliations further underline the potential of these genes described in this study to spread to susceptible strains through horizontal gene transfer mechanisms.

\section{Conclusions}

This study demonstrates the need to combine phenotypic and molecular methods in order to understand important aspects of resistance to $\beta$-lactam antibiotics in developing countries. We recommend that measures be put in place to minimize possible exchange of strains between hospitalized and non-hospitalized patients. Prudent use of $\beta$-lactam antibiotics in developing countries should be advocated and in such countries, the existing empiric treatment regimes should be revised occasionally in order to reflect prevailing resistance phenotypes. Such measures may help to preserve the potency of $\beta$-lactam antibiotics and improve success of chemotherapy. Finally, the diversity of bla genes described in this study is relatively high and majority of genes in circulation among $E$. coli strains investigated have a global-like spread. We recommend that attempts be made to investigate the role of Africa and other developing countries as sources or destinations of $\beta$-lactamase-producing strains.

\section{Methods}

\section{Bacterial strains}

Between 1992 and 2010, our laboratory at the KEMRI Centre for Microbiology Research received 912 E. coli isolates from 13 health centres in Kenya. All the 912 isolates were resistant to penicillins alone (e.g. ampicillin), or a combination of penicillins and different classes of $\beta$-lactam antibiotics. These isolates were from urine (395), blood (202), stool (315) and were obtained from confirmed cases of urethral tract infections (UTIs), septicaemia and diarrhoea-like illnesses respectively. Out of the 912 isolates, 255 (28\%) were obtained between 1992 and 1999 while 657 (72\%) were obtained between 2000 and 2010. This difference was as a result of an increase in isolation rates as a result of better detection and screening techniques in recent years. These isolates were obtained from 350 patients seeking outpatient treatment and 562 were from hospitalised patients. Upon receipt, the isolates were sub-cultured on MacConkey agar (Oxoid, Basingstoke, $\mathrm{U}^{\prime} \mathrm{K}$ ) and species identification done using standard biochemical tests as described before [44]. Ethical clearance to carry out this study was obtained from the KEMRI/National Ethics Committee (Approval: SSC No. 1177).

\section{Antimicrobial susceptibility profiles}

Antimicrobial susceptibility tests were performed for all the 912 isolates using antibiotic discs (Cypress diagnostics, Langdorp, Belgium) on Mueller Hinton agar (Oxoid, Basingstoke, United Kingdom). E. coli ATCC 25922 was included as a control strain on each test occasion. Susceptibility tests were interpreted using the Clinical and Laboratory Standards Institute (CLSI) guidelines [45]. The antibiotics included in this panel were: - ampicillin (AMP, $10 \mu \mathrm{g}$ ), oxacillin (OXA, $30 \mu \mathrm{g}$ ), amoxicillin (AML, $30 \mu \mathrm{g}$ ), cephalothin (KF, $30 \mu \mathrm{g}$ ), cefuroxime (CXM $30 \mu \mathrm{g}$ ), cefotaxime (CTX, $30 \mu \mathrm{g}$ ) and ceftazidime (CAZ, $30 \mu \mathrm{g})$. Other antibiotics included cefepime (FEP, $30 \mu \mathrm{g}$ ), aztreonam (AZT, $30 \mu \mathrm{g}$ ), and cefoxitin (FOX, 30 $\mu \mathrm{g}) . \quad \beta$-lactam $/ \beta$-lactamase inhibitor combinations included amoxicillin/clavulanic acid (AMC, comprising amoxicillin $20 \mu \mathrm{g}$ and clavulanic acid $10 \mu \mathrm{g}$ ), ampicillin/ sulbactam (AMS) combinations in rations of $20 \mu \mathrm{g}$ and $10 \mu \mathrm{g}$ respectively, and piperacillin/tazobactam (TZP) in potency ratio of $100 / 10 \mu \mathrm{g}$ respectively. Imipenem (IM $30 \mu \mathrm{g})$ was used to test susceptibility to carbapenems.

\section{Detection and Interpretation of $\beta$-lactamase phenotype}

Two strategies were used for detection of $\beta$-lactamase phenotypes as detailed in the CLSI guidelines [45], and in other related studies [46]. The first strategy was the double-disc synergy test (m-DDST) in which the $\beta$ lactam antibiotics were placed adjacent to the amoxicillin/clavulanic (AMC) disc at inter-disc distances (centre to centre) of $20 \mathrm{~mm}$. A clear extension of the edge of the disc zones towards the AMC (ghost zones or zones of synergy) was interpreted as positive for ESBL production. In the combined disc method (CDM), tests were 
first done using $\beta$-lactam antibiotics and then repeated using discs containing combinations of $\beta$-lactam/ $\beta$-lactamase inhibitors. A result indicating $\mathrm{a} \geq 5 \mathrm{~mm}$ increase in zone diameter for the $\beta$-lactam $/ \beta$-lactamase inhibitor disc was interpreted as production of ESBLs $[45,46]$. The results from the m-DDST and CDM methods were also used for empiric categorization of strains into NSBL-, IRT-, ESBL- CMT- and pAmpC-like $\beta$-lactamase phenotypes as detailed before [5].

\section{PCR detection of $\beta$-lactamase genes}

Preparation of DNA used as template in PCR reactions was obtained by boiling bacteria suspension from an 8 hr culture at $95{ }^{\circ} \mathrm{C}$ for 5 minutes. The supernatant was stored at $-20^{\circ} \mathrm{C}$ until further use. Subsequent PCR amplifications were carried out in a final volume of 25 $\mu \mathrm{L}$ or $50 \mu \mathrm{L}$. A minimum of $5 \mu \mathrm{L}$ of template DNA and $1 \mu \mathrm{L}$ of $10 \mathrm{mM}$ concentration of both forward and reverse primers were used in PCR reactions. Isolates from our collection that had been found to carry various bla genes in past studies [24,27,47], were used as positive controls in PCR screening for genes of interest. Sterile distilled water or $E$. coli strains susceptible to all $\beta$ lactam antibiotics were used as negative controls. PCR products were analyzed using electrophoresis in $1.5 \%$ agarose gels and stained with ethidium bromide. Visualization of the PCR products was done under UV light and the image recorded with the aid of a gel documentation system (Bio-Rad Laboratories, Hercules, CA, USA).

\section{Selection of isolates for further analysis}

Isolates from each phenotype were selected for further analysis using PCR and sequencing strategies. For phenotypes with a high number of isolates (i.e. more than a hundred strains), at least $56 \%$ of the isolates were selected for further analysis. In order to minimize bias, the isolates selected from each phenotype were proportion to the total number of isolates obtained during each year of isolation (1992 to 2010). Similarly, the number of isolates selected from urine, stool and blood specimen was proportional to the total number of strains isolated from each specimen-type obtained from both hospitalized and non-hospitalized patients. Using this criterion, 586 (64\%) of the 912 isolates were selected for further analysis. Regardless of the source phenotype, all the selected isolates were investigated for carriage of the complete panel of bla genes screened for in this study.

\section{Screening for bla genes}

The strains were screened for genes frequently reported among members of family Enterobacteriaceae [11]. The list of primers used is indicated in Table 4. Consensus primers published in past studies were used for screening for $b l a_{\mathrm{SHV}}$ and $b l a_{\mathrm{TEM}}[48,49]$, bla $a_{\mathrm{CTX}-\mathrm{M}}$ [50] and $b l a_{\mathrm{CMY}}$ [51]. Isolates positive using $b l a_{\mathrm{CTX}-\mathrm{M}}$ consensus primers were screened using primers specific for CTX-M group I to IV as described in a previous study [52]. Isolates positive using the bla $a_{\mathrm{CMY}}$ primers were analyzed using primers for bla $a_{\mathrm{CMY}-1}$-like and $b l a_{\mathrm{CMY}-2}$-like genes [53]. Detection of other $\beta$-lactamase genes was done as previously described for bla $a_{\mathrm{OXA}}$-like [53,54], bla $a_{\mathrm{PER}}$-like [55] , bla $a_{\mathrm{ACC}}$-like [53], bla $a_{\mathrm{VEB}}$-like [56], and

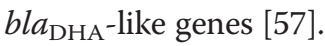

\section{Sequencing}

Amplicons used as template in sequencing reactions were purified using the QIAquick PCR purification kit (Qiagen Ltd., West Sussex, UK). Bi-directional sequencing of the products was done using the DiDeoxy chain termination method in ABI PRISM 310 automatic sequencer (PE Biosystems, Foster City, CA, USA). Consensus primers were used for sequencing except for $b l a_{C T X-M}$ and $b l a_{O X A}$ genes that were sequenced using group-specific primers. Translation of nucleotide sequences was done using bioinformatics tools available at the website of the National Center of Biotechnology Information on http:// www.ncbi.nlm.nih.gov. Alignment of the translated enzyme amino acid sequence was done against that of the wild-type using the ClustalW program on http://www.ebi. ac.uk [58]. Identification of enzyme mutations at amino acid level was determined by comparing the translated amino acid sequence with that of the wild-type enzyme published at http://www.lahey.org/studies.

\section{Competing interests}

None of the authors have competing interests.

\section{Authors' contributions}

JK designed the study, carried out the experiments and wrote the manuscript. SK, BM and PB designed the study and participated in manuscript write-up and review. All authors read and approved the final manuscript.

\section{Authors' information}

JK and SK are research Scientist at the Kenya Medical Research Institute (KEMRI). BMG is Professor at the K.U.Leuven (Faculty of Bioscience Engineering) while PB is a Senior Research Scientist at the Veterinary and Agrochemical Research Centre (VAR)

\section{Acknowledgements}

The authors would like to thank staff and students attached to the CMR-WT unit lab at KEMRI and staff members of Bacteriology unit at VAR-Belgium. This work was supported by a PhD scholarship grant from the Vlaamse Interuniversitaire Raad (VLIR), Belgium (Grant number BBTP2007-0009-1086). This work is published with permission from the Director, KEMRI.

\section{Author details}

${ }^{1}$ Centre for Microbiology Research, Kenya Medical Research Institute, P.O Box 19464-00202, Nairobi, Kenya. ${ }^{2}$ Department of Biosystems, Faculty of Bio-

Science Engineering, Katholieke Universiteit Leuven, Kasteelpark Arenberg 30, B-3001, Heverlee, Belgium. ${ }^{3}$ Veterinary and Agrochemical Research Centre, Groeselenberg 99, B-1180, Ukkel, Belgium. ${ }^{4}$ Department of Virology, Parasitology and Immunology, Faculty of Veterinary Medicine, University of Ghent, Salisburylaan 133, 9820, Merelbeke, Belgium. ${ }^{5}$ Department of 
Pathology, Bacteriology and Poultry Diseases, Faculty of Veterinary Medicine, University of Ghent, Salisburylaan 133, 9820, Merelbeke, Belgium.

Received: 2 February 2012 Accepted: 17 July 2012

Published: 28 July 2012

\section{References}

1. Huang SS, Lee MH, Leu HS: Bacteremia due to extended-spectrum betalactamase-producing Enterobacteriaceae other than Escherichia coli and Klebsiella. J Microbiol Immunol Infect 2006, 39:496-502.

2. Bush K, Jacoby GA, Medeiros AA: A functional classification scheme for beta-lactamases and its correlation with molecular structure. Antimicrob Agents Chemother 1995, 39:1211-1233.

3. Bush K: New beta-lactamases in gram-negative bacteria: diversity and impact on the selection of antimicrobial therapy. Clin Infect Dis 2001 32:1085-1089.

4. Canton R, Coque TM: The CTX-M beta-lactamase pandemic. Curr Opin Microbiol 2006, 9:466-475.

5. Canton R, Morosini MI, de la Maza OM, de la Pedrosa EG: IRT and CMT beta-lactamases and inhibitor resistance. Clin Microbiol Infect 2008 14(Suppl 1):53-62.

6. Jacoby GA, Medeiros AA: More extended-spectrum beta-lactamases. Antimicrob Agents Chemother 1991, 35:1697-1704.

7. Beceiro A, Maharjan S, Gaulton T, Doumith M, Soares NC, Dhanji H, Warner M, Doyle M, Hickey M, Downie G, Bou G, Livermore DM, Woodford N: False extended-spectrum \{beta\}-lactamase phenotype in clinical isolates of Escherichia coli associated with increased expression of OXA-1 or TEM-1 penicillinases and loss of porins. J Antimicrob Chemother 2011, 66:2006-2010.

8. Tristram SG, Hawes R, Souprounov J: Variation in selected regions of blaTEM genes and promoters in Haemophilus influenzae. J Antimicrob Chemother 2005, 56:481-484

9. Nelson EC, Segal H, Elisha BG: Outer membrane protein alterations and blaTEM-1 variants: their role in beta-lactam resistance in Klebsiella pneumoniae. J Antimicrob Chemother 2003, 52:899-903.

10. Lartigue MF, Leflon-Guibout V, Poirel L, Nordmann P, Nicolas-Chanoine MH: Promoters $\mathrm{P} 3, \mathrm{~Pa} / \mathrm{Pb}, \mathrm{P} 4$, and $\mathrm{P} 5$ upstream from bla(TEM) genes and their relationship to beta-lactam resistance. Antimicrob Agents Chemother 2002, 46:4035-4037.

11. Knox JR: Extended-spectrum and inhibitor-resistant TEM-type betalactamases: mutations, specificity, and three-dimensional structure. Antimicrob Agents Chemother 1995, 39:2593-2601.

12. Sirot D, Sirot J, Labia R, Morand A, Courvalin P, Darfeuille-Michaud A, Perroux R, Cluzel R: Transferable resistance to third-generation cephalosporins in clinical isolates of Klebsiella pneumoniae: identification of CTX-1, a novel beta-lactamase. J Antimicrob Chemother 1987, 20:323-334.

13. Henquell C, Chanal C, Sirot D, Labia R, Sirot J: Molecular characterization of nine different types of mutants among 107 inhibitor-resistant TEM betalactamases from clinical isolates of Escherichia coli. Antimicrob Agents Chemother 1995, 39:427-430.

14. Caroff N, Espaze E, Gautreau D, Richet H, Reynaud A: Analysis of the effects of -42 and -32 ampC promoter mutations in clinical isolates of Escherichia coli hyperproducing ampC. J Antimicrob Chemother 2000 45:783-788.

15. da Silva RM, Traebert J, Galato D: Klebsiella pneumoniae carbapenemase (KPC)-producing Klebsiella pneumoniae: a review of epidemiological and clinical aspects. Expert Opin Biol Ther 2012, :663-671.

16. Canton R, Akova M, Carmeli Y, Giske CG, Glupczynski Y, Gniadkowski M, Livermore DM, Miriagou V, Naas T, Rossolini GM, Samuelsen O, Seifert H, Woodford N, Nordmann P: Rapid evolution and spread of carbapenemases among Enterobacteriaceae in Europe. Clin Microbiol Infect 2012, 18:413-431.

17. Nordmann $P$, Dortet L, Poirel L: Carbapenem resistance in Enterobacteriaceae: here is the storm! Trends Mol Med 2012, 18(5):263-272.

18. Nordmann P, Poirel L: Emerging carbapenemases in Gram-negative aerobes. Clin Microbiol Infect 2002, 8:321-331.

19. Coudron PE, Hanson ND, Climo MW: Occurrence of extended-spectrum and $\mathrm{AmpC}$ beta-lactamases in bloodstream isolates of Klebsiella pneumoniae: isolates harbor plasmid-mediated FOX-5 and ACT-1 AmpC beta-lactamases. J Clin Microbiol 2003, 41(2):772-777.

20. Dolejska M, Frolkova P, Florek M, Jamborova I, Purgertova M, Kutilova I, Cizek A, Guenther S, Literak I: CTX-M-15-producing Escherichia coli clone B2-O25b-ST131 and Klebsiella spp. isolates in municipal wastewater treatment plant effluents. J Antimicrob Chemother 2011, 66:2784-2790

21. Eckert C, Gautier V, Arlet G: DNA sequence analysis of the genetic environment of various blaCTX-M genes. J Antimicrob Chemother 2006, 57(1):14-23.

22. Escobar-Paramo P, Grenet K, Le MA, Rode L, Salgado E, Amorin C, Gouriou S, Picard B, Rahimy MC, Andremont A, Denamur E, Ruimy R: Large-scale population structure of human commensal Escherichia coli isolates. Appl Environ Microbiol 2004, 70:5698-5700.

23. Boyle F, Healy G, Hale J, Kariuki S, Cormican M, Morris D: Characterization of a novel extended-spectrum beta-lactamase phenotype from OXA-1 expression in Salmonella Typhimurium strains from Africa and Ireland. Diagn Microbiol Infect Dis 2011, 70:549-553.

24. Kiiru J, Kariuki S, Goddeeris BM, Revathi G, Maina TW, Ndegwa DW, Muyodi J, Butaye P: Escherichia coli strains from Kenyan patients carrying conjugatively transferable broad-spectrum beta-lactamase, qnr, aac(6')$\mathrm{Ib}-\mathrm{cr}$ and $16 \mathrm{~S}$ rRNA methyltransferase genes. J Antimicrob Chemother 2011, 66:1639-1642.

25. Poirel L, Revathi G, Bernabeu S, Nordmann P: Detection of NDM-1producing Klebsiella pneumoniae in Kenya. Antimicrob Agents Chemother 2011, 55:934-936.

26. Pitout JD, Revathi G, Chow BL, Kabera B, Kariuki S, Nordmann P, Poirel L: Metallo-beta-lactamase-producing Pseudomonas aeruginosa isolated from a large tertiary centre in Kenya. Clin Microbiol Infect 2008, 14:755-759.

27. Kariuki S, Corkill JE, Revathi G, Musoke R, Hart CA: Molecular characterization of a novel plasmid-encoded cefotaximase (CTX-M-12) found in clinical Klebsiella pneumoniae isolates from Kenya. Antimicrob Agents Chemother 2001, 45:2141-2143.

28. Kariuki S, Gilks CF, Kimari J, Muyodi J, Waiyaki P, Hart CA: Plasmid diversity of multi-drug-resistant Escherichia coli isolated from children with diarrhoea in a poultry-farming area in Kenya. Ann Trop Med Parasitol 1997, 91:87-94.

29. Miro E, Navarro F, Mirelis B, Sabate M, Rivera A, Coll P, Prats G: Prevalence of clinical isolates of Escherichia coli producing inhibitor-resistant betalactamases at a University Hospital in Barcelona, Spain, over a 3-year period. Antimicrob Agents Chemother 2002, 46:3991-3994.

30. Perez-Moreno MO, Perez-Moreno M, Carulla M, Rubio C, Jardi AM, Zaragoza $\mathrm{J}$ : Mechanisms of reduced susceptibility to amoxycillin-clavulanic acid in Escherichia coli strains from the health region of Tortosa (Catalonia, Spain). Clin Microbiol Infect 2004, 10:234-241.

31. Mendonca N, Leitao J, Manageiro V, Ferreira E, Canica M: Spread of extended-spectrum beta-lactamase CTX-M-producing escherichia coli clinical isolates in community and nosocomial environments in Portugal. Antimicrob Agents Chemother 2007, 51:1946-1955.

32. Rodriguez-Bano J, Lopez-Cerero L, Navarro MD, de Diaz AP, Pascual A: Faecal carriage of extended-spectrum beta-lactamase-producing Escherichia coli: prevalence, risk factors and molecular epidemiology. J Antimicrob Chemother 2008, 62:1142-1149.

33. Carattoli A: Animal reservoirs for extended spectrum beta-lactamase producers. Clin Microbiol Infect 2008, 14(Suppl 1):117-123.

34. Livermore DM, James D, Reacher M, Graham C, Nichols T, Stephens P, Johnson AP, George RC: Trends in fluoroquinolone (ciprofloxacin) resistance in enterobacteriaceae from bacteremias, England and Wales, 1990-1999. Emerg Infect Dis 2002, 8:473-478.

35. Hanson ND, Moland ES, Hong SG, Propst K, Novak DJ, Cavalieri SJ: Surveillance of community-based reservoirs reveals the presence of CTX-M, imported AmpC, and OXA-30 beta-lactamases in urine isolates of Klebsiella pneumoniae and Escherichia coli in a U.S. community. Antimicrob Agents Chemother 2008, 52:3814-3816.

36. Gangoue-Pieboji J, Bedenic B, Koulla-Shiro S, Randegger C, Adiogo D, Ngassam P, Ndumbe P, Hachler H: Extended-spectrum-beta-lactamaseproducing Enterobacteriaceae in Yaounde, Cameroon. J Clin Microbiol 2005, 43:3273-3277.

37. Livermore DM, Canton R, Gniadkowski M, Nordmann P, Rossolini GM, Arlet G, Ayala J, Coque TM, Kern-Zdanowicz I, Luzzaro F, Poirel L, Woodford N: 
CTX-M: changing the face of ESBLs in Europe. $J$ Antimicrob Chemother 2007, 59:165-174.

38. Pitout JD, Thomson KS, Hanson ND, Ehrhardt AF, Moland ES, Sanders CC: beta-Lactamases responsible for resistance to expanded-spectrum cephalosporins in Klebsiella pneumoniae, Escherichia coli, and Proteus mirabilis isolates recovered in South Africa. Antimicrob Agents Chemother 1998, 42:1350-1354.

39. Doi Y, Adams J, O'Keefe A, Quereshi Z, Ewan L, Paterson DL: Communityacquired extended-spectrum beta-lactamase producers, United States. Emerg Infect Dis 2007, 13:1121-1123.

40. Cloeckaert A, Praud K, Doublet B, Bertini A, Carattoli A, Butaye P, Imberechts H, Bertrand S, Collard JM, Arlet G, Weill FX, Nakaya R: Dissemination of an extended-spectrum-beta-lactamase blaTEM-52 gene-carrying Incl1 plasmid in various Salmonella enterica serovars isolated from poultry and humans in Belgium and France between 2001 and 2005. Antimicrob Agents Chemother 2007, 51:1872-1875.

41. Nicolas-Chanoine MH, Blanco J, Leflon-Guibout V, Demarty R, Alonso MP Canica MM, Park YJ, Lavigne JP, Pitout J, Johnson JR: Intercontinental emergence of Escherichia coli clone 025:H4-ST131 producing CTX-M-15. J Antimicrob Chemother 2008, 61:273-281.

42. Bae IK, Lee YN, Lee WG, Lee SH, Jeong SH: Novel complex class 1 integron bearing an ISCR1 element in an Escherichia coli isolate carrying the blaCTX-M-14 gene. Antimicrob Agents Chemother 2007, 51:3017-3019.

43. Hopkins KL, Liebana E, Villa L, Batchelor M, Threlfall EJ, Carattoli A: Replicon typing of plasmids carrying CTX-M or CMY beta-lactamases circulating among Salmonella and Escherichia coli isolates. Antimicrob Agents Chemother 2006, 50:3203-3206.

44. Cowan ST: Cowan and Steel's manual for identification of medical bacteria. 2nd edition. Cambridge: Cambridge University Press; 1985.

45. Clinical and Laboratory Standards Institute (CLSI): Performance standardsfor antimicrobial susceptibility testing; 15th informational supplement (M100-S15). Wayne PA, USA: CLSI: Clinical Laboratory Standards Institute; 2007.

46. Karisik E, Ellington MJ, Pike R, Warren RE, Livermore DM, Woodford N: Molecular characterization of plasmids encoding CTX-M-15 betalactamases from Escherichia coli strains in the United Kingdom. $J$ Antimicrob Chemother 2006, 58:665-668.

47. Kariuki S, Revathi G, Corkill J, Kiru J, Mwituria J, Mirza N, Hart CA: Escherichia coli from community-acquired urinary tract infections resistant to fluoroquinolones and extended-spectrum beta-lactams. J Infect Dev Ctries 2007, 1:257-262.

48. Arlet G, Rouveau M, Philippon A: Substitution of alanine for aspartate at position 179 in the SHV-6 extended-spectrum beta-lactamase. FEMS Microbiol Lett 1997, 152:163-167.

49. Arlet G, Brami G, Decre D, Flippo A, Gaillot O, Lagrange PH, Philippon A: Molecular characterisation by PCR-restriction fragment length polymorphism of TEM beta-lactamases. FEMS Microbiol Lett 1995, 134:203-208.

50. Lartigue MF, Poirel L, Nordmann P: Diversity of genetic environment of bla(CTX-M) genes. FEMS Microbiol Lett 2004, 234:201-207.

51. Winokur PL, Brueggemann A, DeSalvo DL, Hoffmann L, Apley MD, Uhlenhopp EK, Pfaller MA, Doern GV: Animal and human multidrugresistant, cephalosporin-resistant salmonella isolates expressing a plasmid-mediated CMY-2 AmpC beta-lactamase. Antimicrob Agents Chemother 2000, 44:2777-2783.

52. Pitout JD, Hossain A, Hanson ND: Phenotypic and molecular detection of CTX-M-beta-lactamases produced by Escherichia coli and Klebsiella spp. J Clin Microbiol 2004, 42:5715-5721.

53. Hasman H, Mevius D, Veldman K, Olesen I, Aarestrup FM: beta-Lactamases among extended-spectrum beta-lactamase (ESBL)-resistant Salmonella from poultry, poultry products and human patients in The Netherlands. $J$ Antimicrob Chemother 2005, 56:115-121.

54. Olesen I, Hasman H, Aarestrup FM: Prevalence of beta-lactamases among ampicillin-resistant Escherichia coli and Salmonella isolated from food animals in Denmark. Microb Drug Resist 2004, 10:334-340.

55. Poirel L, Karim A, Mercat A, Le Thomas I, Vahaboglu H, Richard C, Nordmann P: Extended-spectrum beta-lactamase-producing strain of Acinetobacter baumannii isolated from a patient in France. $J$ Antimicrob Chemother 1999, 43:157-158.

56. Kim JY, Park YJ, Kim SI, Kang MW, Lee SO, Lee KY: Nosocomial outbreak by Proteus mirabilis producing extended-spectrum beta-lactamase VEB-1 in a Korean university hospital. J Antimicrob Chemother 2004, 54:1144-1147.
57. Verdet C, Benzerara Y, Gautier V, Adam O, Ould-Hocine Z, Arlet G: Emergence of DHA-1-producing Klebsiella spp. in the Parisian region: genetic organization of the ampC and ampR genes originating from Morganella morganii. Antimicrob Agents Chemother 2006, 50:607-617.

58. Thompson JD, Higgins DG, Gibson TJ: CLUSTAL W: improving the sensitivity of progressive multiple sequence alignment through sequence weighting, position-specific gap penalties and weight matrix choice. Nucleic Acids Res 1994, 22:4673-4680.

doi:10.1186/1471-2180-12-155

Cite this article as: Kiru et al:: Analysis of $\beta$-lactamase phenotypes and carriage of selected $\beta$-lactamase genes among Escherichia coli strains obtained from Kenyan patients during an 18-year period. BMC Microbiology 2012 12:155.

\section{Submit your next manuscript to BioMed Central and take full advantage of:}

- Convenient online submission

- Thorough peer review

- No space constraints or color figure charges

- Immediate publication on acceptance

- Inclusion in PubMed, CAS, Scopus and Google Scholar

- Research which is freely available for redistribution

Submit your manuscript at www.biomedcentral.com/submit
Biomed Central 